\title{
The Knowledge and Practices of Self-Care Capabilities among Geriatric Population
}

\author{
Jaya Koirala1,7*, Raddi SA², Shivaswamy MS ${ }^{3}$, Koirala D4, Koirala A5, \\ Koirala $S^{6,7}$ and Koirala N7,8 $^{7}$ \\ ${ }^{1}$ Nursing Superintendent, Birat Medical College Teaching Hospital, Nepal \\ ${ }^{2}$ OBG Nursing, KLE Institute of Nursing Sciences, KLE Academy of Higher Education \& \\ Research (Deemed to be University), India,
}

Research article

Volume 4 Issue 1

Received Date: January 11, 2019

Published Date: February 04, 2019

DOI: $10.23880 / \mathrm{ijbp}-16000144$

${ }^{3} J N$ Medical College, KLE Academy of Higher Education \& Research (Deemed to be University), India

${ }^{4}$ Kist Medical College, Nepal

${ }^{5}$ Valley College, Kathmandu, Nepal

6Universal College of Medical Sciences, Nepal

${ }^{7}$ Dr. Koirala Research Institute for Biotechnology and Biodiversity, Nepal

${ }^{8}$ Department of Scientific Affairs, Grasella Herbs Ltd, Nepal

*Corresponding author: Ms. Jaya Koirala, Nursing Superintendent, Birat Medical College and Teaching Hospital, Tankisinuwari, Morang, Nepal, Email: jayakoirala32@gmail.com / koirala.biochem@gmail.com

\section{Abstract}

Introduction: Aging is a universal process. In the words of Seneca - "old age is an incurable disease". Sir James Sterling Ross Commented "you do not heal old age, you protect it, you promote it and you extend it". The number of old age people indwelling in the world is increasing rapidly. Some of them tackle the situation in a more pleasant way. But the majority of the geriatric clients are seeing it in negative manner. Here comes the importance of the self-care activities. According to the Oxford English Dictionary, old age is the time of life when you are old, above the age group of 60 years.

Objective: The Objectives of the study were to assess the knowledge of self-care capabilities among geriatric population in Handignur village in Belagavi district of Karnataka state in India, to find out the practices of self-care capabilities among geriatric population in Handignur village and to find an association between knowledge and practices regarding self-care capabilities among geriatric population in Handignur village.

Methodology: Descriptive survey design was used for the study. A total of 252 study subjects above 60 years were selected for the study by using purposive sampling technique. The setting selected for the present study was Handignur village in Belagavi district, Karnataka state, India. Data collection was done using items assessing knowledge regarding self-care capabilities and check list; related to items assessing practice. 


\section{International Journal of Biochemistry \& Physiology}

Results: Out of 252 subjects surveyed, 105(41\%) were having good knowledge, 90(35.7\%) were having average knowledge and only 57(22.6\%) were having poor knowledge regarding self-care capability. Among practices, majority gave their feedback in terms of not following the practices mentioned in the checklist. There was a strong association between knowledge and variables like age, occupation, monthly income, gender, type of family, diet, education, habits, health conditions, but religion did not show any statistically significant association regarding self care capability.

Conclusion: The study aids as a milestone to provide optimal care for the growing number of elderly people. It also reflects the attitude practiced in the past and modified in the future by the nurses. The study also enhances the impact of the age, gender, occupation, socio-economic status, health condition and activity for the daily living in the health care system of geriatric population.

Keywords: Geriatric population; Knowledge; Practice; Self-care capability

\section{Introduction}

Aging is the natural process. In the words of Seneca "Old age is an incurable disease". According to Sir James Sterling Ross - "You do not heal old age. You protect it; you promote it; you extend it". According to the Oxford English Dictionary -"old age is the time of life when you are old, above the age group of 60 years" [1].

Old age is not synonymous with ill health. Live well, Live Long was the theme of World Elder's Day celebrated on the $1^{\text {st }}$ October 2009. Geriatric Health pertains to medical care to the elderly population. It is generally accepted to call an individual over the age of 60 years as an elderly. The elderly age group can be divided into (i) younger elderly people between 60-74 years of age, (ii) middle old people between 75-84 years of age, (iii) old elderly people over the age of 85 [2].

Ageing is for the individuals regarded as something unpleasant, useful, unnecessary, and unwanted. The old aged people feel themselves to be useless. Some elderly people are satisfied by watching the beauty of nature their aging. ${ }^{3}$ The elderly are a precious asset for any country with rich experience and wisdom; they contribute their might for sustenance and progress of the nation [3].

India ranks $4^{\text {th }}$ globally in terms of absolute size of the elderly population. The country is not adequately equipped to look after their special health needs and the changing traditional value system. A feeling is now growing among the aged persons that the attitude of the younger generation towards them is not as desired. The traditional sense of duty and obligation of the younger generation towards their older generation is being eroded. The older generation is caught between the decline in traditional values on one hand and the absence of adequate social security system on the other [4]. Many Non-Communicable Diseases create a significant clinical and economic burden on the society [5].

Self-care means to take care of his/her one own self and it is a part of an individual lifestyle, which is shaped by values and beliefs learned in specific cultures and personal experience. Self-care is the personal care that individuals require each day to regulate their own functioning and it is the key to health and illness care. A traditional concept of Self-care activities associated with health promotion and daily activities, such as exercise, nutrition and relaxation, etc [6].

The self-care behaviors are learnt that a person performs self-care activities to maintain life, health and wellbeing. Self-care has emerged as a multidimensional concept constructed from a wide collection of perspectives. Alongside such developments the World Health Organization (WHO) has formed a broad definition of self-care as "what people do for oneself to establish and maintain health, prevent and deal with illness' [7].

The major International Health Agencies like; WHO (World Health Organization) is focused to attainment by all people of the highest level of health, FAO (Food and Agriculture Organization) is focused to help nations raise their living standards, In 1931 Rockefeller Foundation began its activities to promote the well-being of mankind throughout the world, In 1920 Indian Red Cross Society was established to improve health; prevention of disease and mitigation of suffering and service for mankind in peace \& war. All these Health Agencies are mainly focused about health of the Nations, so "Health is wealth' $[8,9]$. Care of the aged is very important for the care givers, is to 


\section{International Journal of Biochemistry \& Physiology}

gain knowledge, nursing skills and right attitude in order to give skilled nursing care to the people, should assess the immediate and long term needs or problems of the aged and their families always face, supporting, advising and guiding and plan with family in providing the total care including rehabilitation [8].

Suggestion of care givers on various aspects of elderly decide where and how to lead the remaining life, continue to have supportive, close, warm relationship with the spouse or close relatives to have safe and comfortable dwelling according to one's economic status, maintain a high degree of health, physical and emotional by getting regular health examination and needed medical and dental care, eating balanced diet and maintain good personal hygiene, maintaining contact with children, grandchildren and other kinsmen, finding emotional satisfaction with them work out for significant, philosophy of life, finding comfort in a philosophy or religion, adjust living standards to retirement, income, supplement income with remunerative activities ${ }^{9}$.With a rise in the number of elders in the community, very little is being done in planning and providing care for the ageing population [10].

Nurses play a vital role in guiding the self-care activities of old age which includes physical and mental care. Community health nurse has to make visits in houses and old age homes for the same. The main aspects included must be regular physical activity, diet, weak bones, oral care, and prevention of accidents, sight, hearing, all health problems and common ailments like incontinence, constipation etc [11-13].

\section{Material and Methods}

Descriptive survey design was used for the study. A total of 252 samples were selected for the study by using purposive sampling technique. The population comprised of both male and female geriatric population above 60 years. Setting selected for the present study was Handignur village of Belagavi district, Karnataka state, India. Data collection was done using items assessing knowledge regarding self-care capabilities and checklist related to items assessing practice. A structured interview schedule was used as a tool for data collection; the data were tabulated and analysed according to the objectives of the studying descriptive and inferential statistics.

\section{Results}

In the present study with 252 senior citizens residing in Handignur village of Belagavi district, Karnataka state of India, it was found that maximum 132 (58.38\%) 60-69 years, $94(37 \%)$ were between 70-79 years of age, 20 (9\%) were found between 80-89 years and only $6(2 \%)$ were above 90 years of age. 134 (53.2\%) were females and 118 (46.2\%) were males. All 252 (100\%) were Hindus.

Most 215 (85.3\%) depended on agriculture for their livelihood, whereas 20 (7.93\%) were laborers, 10 (3.96\%) were retired Government servants and only 7 (2.7\%) did some business. Most 196 (78\%) belonged to nuclear families and only 56 (22\%) were staying in joint family. Maximum 156 (62\%) were vegetarians and 96 (38\%) were consuming mixed diet. Most 159 (63\%) did not have latrine in their house and they practiced open field defecation, whereas only 93 (37\%) possessed latrines in their house.

Maximum 153 (60\%) were having monthly income of Rs. 2,000 - 3,000, 66 (26.19\%) were having monthly income of Rs. 5,000 \& above, 19 (7.53\%) had monthly income of Rs.3,001-4,000 and only 18 (7.14\%) had income of Rs.3,001-4,000 / month. Maximum 207 (82\%) were illiterate, $27(11 \%)$ had completed their primary education, $11(4 \%)$ did their secondary education and only 7 (3\%) had completed PUC. Around 125 (49.6\%) were suffering from high blood pressure, 80 (31.7\%) with diabetes, 58 (23\%) suffered from asthma, 53 (21\%) suffered from other minor ailments, 20 (8\%) reported with problems of arthritis, 14 (5.6\%) were having heart problems and only $4(1.5 \%)$ reported with cancer. 91 (36.1\%) said they were having habit of tobacco chewing, $59(23.4 \%)$ had habit of chewing pan, $50(19.8 \%)$ found with smoking habits, $31(12.3 \%)$ consumed alcohol and only $21(8.3 \%)$ presented themselves without any bad habits.

\begin{tabular}{|c|c|c|}
\hline Variables & Frequency (f) & Percentage (\%) \\
\hline \multicolumn{3}{|c|}{ Age in Years } \\
\hline $60-69$ & 132 & 52.38 \\
\hline $70-79$ & 94 & 37.3 \\
\hline $80-89$ & 20 & 8 \\
\hline $90 \&$ above & 5 & 2 \\
\hline \multicolumn{3}{|c|}{ Gender } \\
\hline
\end{tabular}

Jaya Koirala, et al. The Knowledge and Practices of Self-Care Capabilities among Geriatric Population. Int J Biochem Physiol 2019, 4(1): 000144. 


\section{International Journal of Biochemistry \& Physiology}

\begin{tabular}{|c|c|c|}
\hline Male & 118 & 46.8 \\
\hline Female & 134 & 53.2 \\
\hline \multicolumn{3}{|c|}{ Religion } \\
\hline Hindu & 252 & 100 \\
\hline \multicolumn{3}{|c|}{ Occupation } \\
\hline Agriculture & 215 & 85.31 \\
\hline Labour & 20 & 7.93 \\
\hline Govt. Retired / Pension & 10 & 3.96 \\
\hline Business & 7 & 2.77 \\
\hline \multicolumn{3}{|c|}{ Type of Family } \\
\hline Nuclear & 196 & 78 \\
\hline Joint & 56 & 22 \\
\hline \multicolumn{3}{|c|}{ Diet } \\
\hline Vegetarian & 156 & 62 \\
\hline Mixed & 96 & 38 \\
\hline \multicolumn{3}{|c|}{ Type of Latrine } \\
\hline Household Toilet & 93 & 37 \\
\hline Outfield Defecation & 159 & 63 \\
\hline \multicolumn{3}{|c|}{ Income } \\
\hline Rs.2000-3000/ month & 153 & 60 \\
\hline Rs.3001 - $4000 /$ month & 19 & 7.53 \\
\hline Rs.4001 - $5000 /$ month & 18 & 7.14 \\
\hline Rs.5001 \& above & 66 & 26.19 \\
\hline \multicolumn{3}{|c|}{ Educational Status } \\
\hline Illiterate & 207 & 82 \\
\hline Primary Education & 27 & 11 \\
\hline Secondary Education & 11 & 4 \\
\hline PUC \& above & 7 & 3 \\
\hline
\end{tabular}

Table 1: Socio-demographic characteristics of the geriatric people.

Figure 1 shows that around 125 (49.6\%) were suffering from high blood pressure, 80 (31.7\%) with diabetes, 58 (23\%) suffered from Asthma, 53 (21\%) suffered from other minor ailments, 20 (8\%) reported with problems of arthritis, $14(5.6 \%)$ were having heart problems and only $4(1.5 \%)$ reported with cancer.

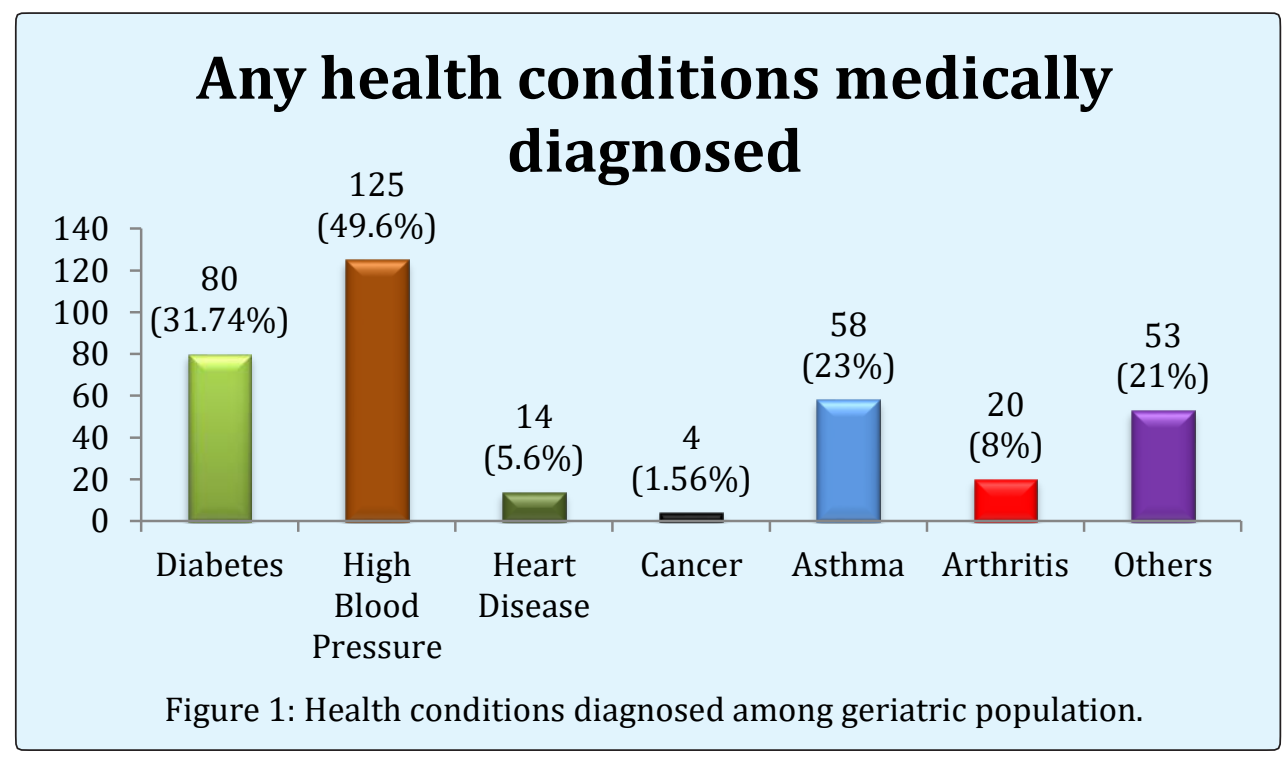




\section{International Journal of Biochemistry \& Physiology}

Figure 2 shows that 91 (36.1\%) said they were having habit of tobacco chewing, $59(23.4 \%)$ had habit of chewing pan, 50 (19.8\%) found with smoking habits, 31
(12.3\%) were alcoholic and only $21(8.3 \%)$ presented themselves without any bad habits.

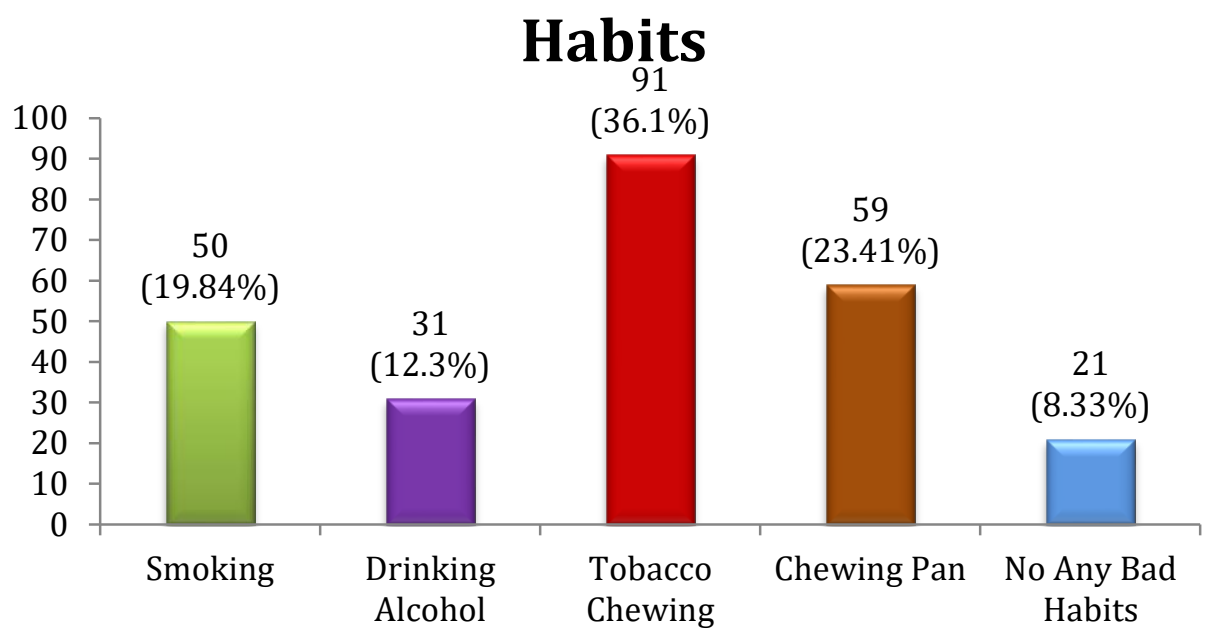

Figure 2: Bad habits among geriatric population.

\section{Knowledge Regarding Self-Care Capability among Geriatric People}

Figure 3 depicts that out of 252 subjects surveyed, 105 (41.6\%) were having good knowledge, 90 (35.7\%) were having average knowledge and only 57 (22.6\%) were having poor knowledge regarding self-care capability as measures by the knowledge questionnaire. Total score was 23 , among which score of $18-23$ was considered good knowledge, 7 - 17 was considered average knowledge and score of $0-6$ was considered poor knowledge.

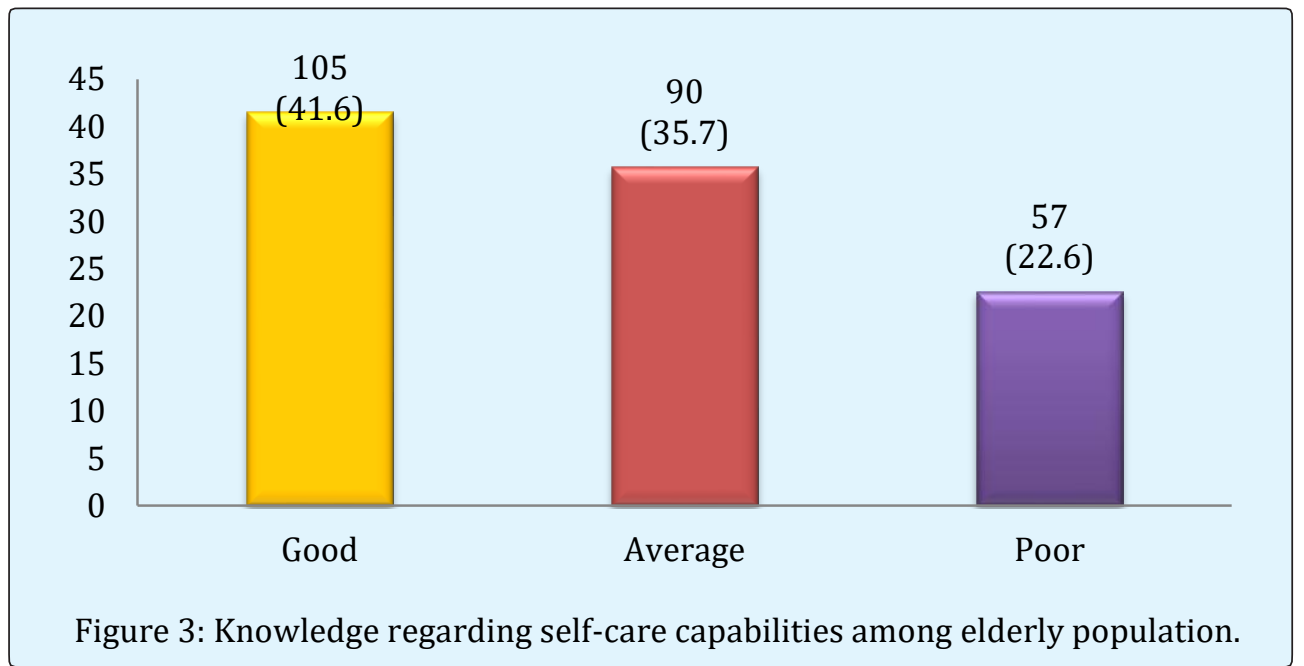

\section{Practice Regarding Self-Care Capability among Geriatric People}

Figure 4 shows practices of geriatric population, among 252 subjects surveyed, 214 (85\%) and 96 (38\%) said they took bath daily and had nutritious food respectively, whereas only $38(15 \%)$ and maximum 156 (62\%) expressed that they didn't take daily bath and didn't consume nutritious food every day. $170(67.4 \%)$ 


\section{International Journal of Biochemistry \& Physiology}

and $82(32.5 \%)$ said they went for regular health check up and took medications as prescribed by the doctor respectively, whereas $82(32.5 \%)$ and $46(18.3 \%)$ said they didn't opt for regular health checkup and they didn't take medications prescribed by the doctor respectively. Almost $213(84.5 \%)$ reported their health problems to doctor, whereas only $39(15.5 \%)$ didn't report to the doctor. $214(84.9 \%)$ and $207(82.1 \%)$ expressed that they adjusted themselves with decreased self-care capability and disease conditions, whereas $38(15.1 \%)$ and 45 (17.4\%) said they didn't. Maximum 216 (85.7\%) and 76 (31.3\%) said they were satisfied with assistance provided by family members and performed ROM exercises every day, whereas $36(14.3 \%)$ and $173(68.7 \%)$ said they didn't. 192 (76.2\%) and 209 (82.9\%) said they involved themselves in social activities \& maintained food hygiene, whereas $60(23.8 \%)$ and $43(17.1 \%)$ said they were not interested. $169(67 \%)$ and $205(81.3 \%)$ said they needed assistance in performing their daily activities and they consumed adequate water respectively, whereas 83 (33\%) and $47(18.3 \%)$ said no for these practices. Maximum $209(82.9 \%)$ and $222(82.1 \%)$ said they had adequate rest and sleep, regular bowel and bladder habits, whereas $43(17.1 \%)$ and $30(11.9 \%)$ expressed that they didn't. Around 227 (90\%) and 20 (83\%) expressed that they used safe water for drinking and maintained safer environment at home, whereas 25 $(9.9 \%)$ and $42(17 \%)$ said they didn't have such facility. $220(87 \%)$ showed interest in engagement in religious activities and only 32 (13\%) didn't show interest. Regarding vaccination, 120 (47.6\%) said they took vaccination for prevention of any diseases and 132 (52.4\%) said they didn't take. All 252 (100\%) of the geriatric population expressed that they took medicines without doctor's order.

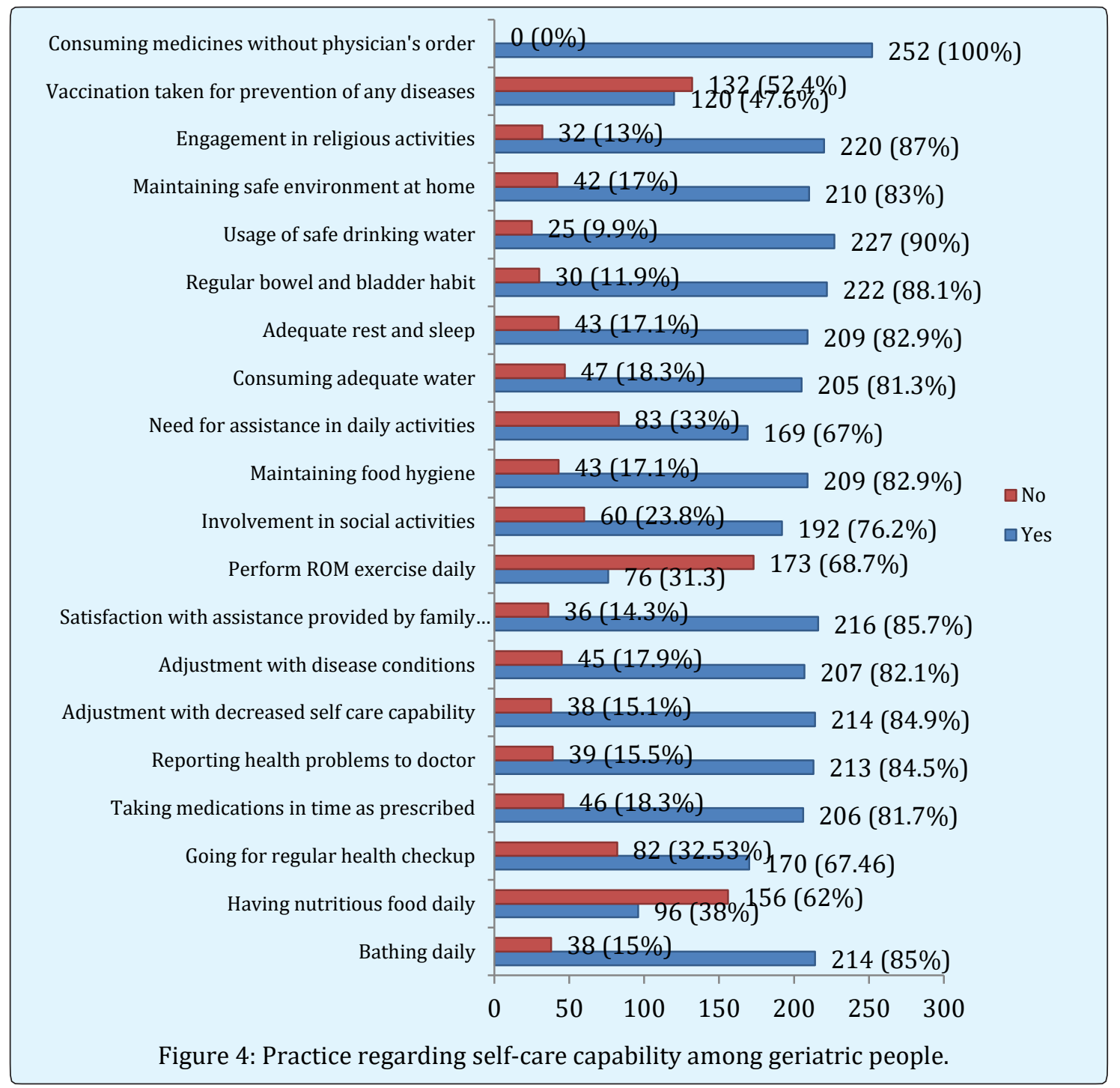

Jaya Koirala, et al. The Knowledge and Practices of Self-Care Capabilities among Geriatric Population. Int J Biochem Physiol 2019, 4(1): 000144. 


\section{International Journal of Biochemistry \& Physiology}

\section{Association of Knowledge Scores of Elderly Population with Selected Demographic Variables}

Chi-square test was computed to find out the association of knowledge scores of elderly population with selected demographic variables. Test results were, Chi-square value at (12.592) for age, occupation, monthly income were 22.6, 34.9 and 64.4 respectively, which showed a strong association between knowledge and these demographic variables. Chi-square value at (5.991) for gender, type of family, diet and type of latrine were 44, $10.9,14.6$ and 15.7 respectively, which showed a strong association between knowledge and these demographic variables. Chi-square value at (9.49) for religion was 7.88, which did not show association; hence they were independent of each other. Chi-square value at (15.51) for education and habits were 29.3 and 40.4, which showed association between knowledge and demographic variables. Chi-square value at (18.31) for health conditions diagnosed was 25.9 which showed association. Hence except religion, all other variables showed statistically significant association with knowledge.

\section{Association of Knowledge Scores of Elderly Population with Selected Demographic Variables}

Chi-square test was computed to find out the association of knowledge scores of elderly population with selected demographic variables. Test results were, Chi-square value at (12.592) for age, occupation, monthly income were 22.6, 34.9 and 64.4 respectively, which showed a strong association between knowledge and these demographic variables. Chi-square value at (5.991) for gender, type of family, diet and type of latrine were 44 , $10.9,14.6$ and 15.7 respectively, which showed a strong association between knowledge and these demographic variables. Chi-square value at (9.49) for religion was 7.88, which did not show association; hence they were independent of each other. Chi-square value at (15.51) for education and habits were 29.3 and 40.4, which showed association between knowledge and demographic variables. Chi-square value at (18.31) for health conditions diagnosed was 25.9 which showed association. Hence except religion, all other variables showed statistically significant association with knowledge.

\section{Discussion}

The study intended to find the knowledge and practices of geriatric population regarding self-care capability. The findings of the study have been discussed with reference to the objectives.

\section{Demographic Variables}

In the present study with 252 senior citizens residing in Handignur village of Belagavi district, Karnataka state of India, it was found that more than half of the person were aged 60-69 year and more than one-third were between 70-79 years of age. Among them, male and female were nearly in equal number. Everyone belonged to Hindu religion.

Nearly 9 out or 10 people depended on agriculture for their livelihood. More than two-third of the geriatric population belonged to nuclear families. Nearly two third of the geriatric persons were vegetarians and other onethird consumed mixed diet. Also two-third of them did not have latrine in their house and they practiced open field defecation, where other one-third possessed latrines in their house.

Nearly $3 / 5^{\text {th }}$ of the geriatric families had had monthly income of Rs. 2,000 - 3,000 while other one fifth had monthly income of Rs. 5,000 \& above. More than four-fifth of the geriatric population were illiterate. Nearly half of the geriatric persons were suffering from high blood pressure, one-third with diabetes, more than one-fifth suffered from asthma, one-fifth suffered from other minor ailments, and few had problems of arthritis, heart problems and cancer. More than one-third said they were having habit of tobacco chewing, more than one-fifth had habit of chewing pan, one fifth had smoking habits, more than 1 out of 10 consumed alcohol and only few had presented themselves without any bad habits.

\section{Knowledge Regarding Self-Care Capability among Geriatric People}

Survey revealed that nearly half had good knowledge; other one-third had average knowledge. More than onefifth had poor knowledge regarding self-care capability as measures by the knowledge questionnaire. Similar findings were found in a study conducted by Nguyen et al. [3-5].

\section{Association of Knowledge Scores of Elderly Population with Selected Demographic Variables}

Chi-square test was computed to find out the association of knowledge scores of elderly population with selected demographic variables. Test results were, Chi-square value at (12.592) for age, occupation, monthly income were 22.6, 34.9 and 64.4 respectively which showed a strong association between knowledge and these demographic variables. Chi-square value at (5.991) 


\section{International Journal of Biochemistry \& Physiology}

for gender, type of family, diet and type of latrine were 44, $10.9,14.6$ and 15.7 respectively which showed a strong association between knowledge and these demographic variables. Chi-square value at (15.51) for education and habits were 29.3 and 40.4 which showed association between knowledge and demographic variables. Chisquare value at (18.31) for health conditions diagnosed was 25.9 , which showed association.

Association between knowledge and selected demographic variables showed a strong association with age, gender, occupation, type of family, diet, type of latrine, monthly income, education, health conditions, habits and knowledge, whereas only religion did not show any association with knowledge.

Nurse can provide health education to provide knowledge regarding self-care practices to geriatric population about the process of aging, physiological changes happening in the body and how to adjust with the various changes in life through education programmes [14]. They also can conduct geriatric clinics in the community so as to rule out the challenges and problems faced by the geriatric population. Nursing administrators can conduct special geriatric survey conduct various programmes related to the welfare of the old age people and develop necessary educational material [14]. Similar study may be replicated on large sample and comparative study may be conducted between urban and rural community $[15,16]$.

Limitations of the Study: The present study was limited to only 252 geriatric people residing in one village, so it may not be representative of entire state or the country.

Acknowledgement: I would like to thank all the study subjects who gave their valuable time and participated in this study, without their cooperation this study would not have been possible.

\section{References}

1. Prakash R, Chodharu SK, Shankar singh U (2004) A Study of Morbidity Pattern among Geriatric Population in An Urban Area of Udaipur Rajasthan. Indian journal of Community Medicine 29(1): 1-35.

2. Gale Robinson Smith, Johnston MV, Allen J (2000) Self-care self-efficacy, quality of life, and depression after stroke. The journal of Archives of Physical Medicine and Rehabilitation 81(4): 460-464.
3. Nguyen HT, Zonderman AB (2006) Relationship between age and aspects of depression: consistency and reliability across two longitudinal studies. Psychol Aging 21(1): 119-126.

4. Dey S, Nambiar S, Lakshmi JK, Sheikh K, Srinath Reddy K (2012) Health of the Elderly in India: Challenges of Access and Affordability. Washington (DC): National Academies Press (US).

5. Hoy B, Wagner L, Hall Eo (2007) Self- care as a health resource of elders: an integrative review of the concept. Scand J Caring Sci 21(4): 456-466.

6. Koc Z (2015) The Investigation of factors that influence self-care agency and daily life activities among the elderly in the northern region of Turkey. National Center for Biotechnology Information Collegian 22: 251-258.

7. Horgas AL, Wilms HU, Baltes MM (1998) Daily Life in Very Old Age: Everyday Activities as Expression of Successful Living. Gerontologist 38(5): 556-568.

8. Wang TF, Lu CH, Chen IJ, Yu S (2008) Sexual knowledge, attitudes and activity of older people in Taipei, Taiwan. J Clin Nurs 17(4): 443-450.

9. Henry-Sánchez JT, Kurichi JE, Xie D, Pan Q, Stineman MG (2012) Do Elderly People at More Severe Activity of Daily Living Limitation Stages Fall More? Am J Phys Med Rehabil 91(7): 601-610.

10. Cabrita M, Lousberg R, Tabak M, Hermens HJ, Vollenbroek-Hutten MM (2017) An exploratory study on the impact of daily activities on the pleasure and physical activity of older adults. Eur Rev Aging Phys Act 14: 1.

11. Cherry A Karl (1982) The Effect of an exercise Program on Self- Care Activities for the Institutionalized Elderly. Journal of Gerontological Nursing 8: 282-285.

12. Altintop I, Tatli M (2018) Physical abuse of the elderly: a 4-year retrospective evaluation in the emergency department. Journal of the Japanese Psychogeriatric Society 19(1): 10-15.

13. Zhou S, Zhou R, Zhong T, Li R, Tan J, et al. (2014) Association of Smoking and Alcohol Drinking with Dementia Risk Among Elderly Men in China. Curr Alzheimer Res 11(9): 899-907. 


\section{International Journal of Biochemistry \& Physiology}

14. Jadczak AD, Tam KL, Visvanathan R (2018) Educating Medical Students in Counselling Older Adults about Exercise: The Impact of a Physical Activity Module. The journal of Fertility and Aging 7(2): 113-119.

15. Kastner M, Cardoso R, Lai Y, Treister V, Hamid JS, et al. (2018) Effectiveness of interventions for managing multiple high-burden chronic diseases in older adults: a systematic review and meta-analysis. CMAJ 190(34): E1004-E1012.

16. Wang Q, Zhang X, Fang L, Guan Q, Guan L, et al. (2018) Prevalence, awareness, treatment and control of diabetes mellitus among middle-aged and elderly people in a rural Chinese population: A crosssectional study. Journal of PLoS 3(6): e0198343.

17. Ástvaldsdóttir Á, Boström AM, Davidson T, Gabre P, Gahnberg L, et al. (2018) Oral health and dental care of older persons-A systematic map of systematic reviews. Gerodontology 35(4): 290-304.

18. Engelheart S, Brummer R (2018) Assessment of nutritional status in the elderly: a proposed functiondriven model. Food Nutr Res 62: 1366. 